\title{
Accreditation Of Project Management Programs Through Global Accreditation Center Of PMI
}

Moe Shahdad, University of Maryland University College, USA

Robert Ouellette, University of Maryland University College, USA

\begin{abstract}
In November 2009, the project management program at the Graduate School of the University of Maryland University College (UMUC) was accredited by the Global Accreditation Center (GAC) of the Project Management Institute. The accreditation process has had a substantially positive impact on both program quality and contents coverage of our program. It has also resulted in a continuous quality improvement process, which is now in place and is expected to bring about improved outcomes for years to come. This paper describes the accreditation process, requirements, and the strategy and approach adopted by the Graduate School of UMUC to respond to accreditation requirements.
\end{abstract}

Keywords: Program Accreditation; Project Management

\section{ACCREDITATION OBJECTIVES AND PROCESS}

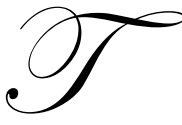

his section describes, from the GAC viewpoint, the objectives of accreditation and the process that an institution has to follow to become accredited. The process starts by applying for accreditation and, for a successful applicant, finishes by receiving a letter of accreditation from the GAC.

The GAC maintains a standard for accreditation of project management programs, and has the authority to accredit institutions that conform to this standard. The accreditation standard is specified in the GAC's Handbook of Accreditation ${ }^{1}$, which is now in its third edition. UMUC applied and was accredited under the second edition of the Handbook, which was in effect at the time.

The ultimate objective of the GAC is to advance excellence in project management education through a performance-based standard that promotes program quality and expands coverage of program contents. In addition, accreditation provides a path for continuous program improvement, as an accredited program needs to be reaccredited once every seven years. Furthermore, the accredited institution must prepare annual reports, demonstrating that it is on its path to meet strategic goals of the program, as outlined at the time of its accreditation. accredited.

The GAC accredits bachelors, masters, and doctoral programs. Certificates and concentrations cannot be

To start the accreditation process, the applicant institution must send a letter of intent to the GAC, specifying the degree programs that are to be accredited, reasons for seeking accreditation, the approximate timeframe for preparing a self-study report, as well as other relevant information. Prior to application for accreditation, the GAC requires that the applicant institution be accredited by a regional accreditation body. UMUC was first accredited by the Middle States Commission on Higher Education in 1946, and most recently it was reaccredited in $2006^{2}$.

\footnotetext{
${ }^{1}$ Project Management Institute. (2007). Handbook of Accreditation of Degree Programs in Project Management. Newtown Square, PA: Project Management Institute.

${ }^{2}$ University of Maryland University College. (2006). Middle states self-study report. Adelphi, MD: Office of the Provost.
} 
Within six months from GAC's acceptance of the letter of intent, the applicant must submit a self-study report, specifying how the applicant meets the requirements of the accreditation standard, as set forth in the Handbook of Accreditation.

Shortly after the self-study report is submitted, the GAC will assign a three-person team for an on-site visit to the applicant institution. The purpose of this visit is to clarify and verify the contents of the self-study report. The visiting team reviews all course materials, including textbooks, lecture notes, students' assignments, and feedback to students. They interview program faculty, students, and alumni, in addition to the units that support teaching and learning. These include library, student support services, technology infrastructure, and other applicable facilities.

At the end of their visit, the team briefs the host institution on their visit. Within a month after the onsite visit, the team sends a statement of factual information, collected during their visit to the applicant institution, for review and any necessary corrections. The purpose of this review is to make sure that the institutional information, presented in the final recommendations of the team to the GAC, is accurate. Shortly after this review, the team will forward its recommendations to the GAC for final review and approval.

In the case of a positive recommendation and approval by the GAC, it is likely that the visiting team would recommend changes to the way the program is administered. Such recommendations would have to be implemented and reported as part of the yearly annual reports.

\section{INSTITUTIONAL ORGANIZATION}

The University of Maryland University College is one of the 11 degree-granting institutions that constitute the University System of Maryland. Founded in 1947, UMUC is one of the leading public adult and continuing higher education institutions in the United States. Using innovative delivery models and technological resources, especially those of the Internet and Worldwide Web, UMUC provides both undergraduate and graduate courses and degree programs to students throughout the United States and the world, including U.S. military personnel and their families stationed in European and Asian countries.

Administration of the Project Management curriculum is housed within the Information and Technology Systems (ITS) Department of UMUC's Graduate School of Management and Technology. The ITS Department, one of four departments in the Graduate School, oversees the following degree programs:

- $\quad$ Master of Science in Information Technology

- $\quad$ Master of Science in Technology Management

- $\quad$ Master of Science in Environmental Management

- $\quad$ Master of Science in Biotechnology

- $\quad$ Master of Distance Education

Most degrees offer a number of specializations. The Project Management Program is available as a specialization under three master's degree programs. Two ITS programs that offer the Project Management specialization are the MS in Information Technology and the MS in Technology Management degrees. Project Management is also an available specialization under the Master of Science in Management degree, housed in the Management, Accounting and Finance (MAF) Department in the Graduate School.

\section{DEGREE PROGRAMS PRESENTED FOR ACCREDITATION}

The following three master's degree programs, all with Project Management Specialization, were presented for accreditation:

- $\quad$ Master of Science in Management

- $\quad$ Master of Science in Technology Management

- $\quad$ Master of Science in Information Technology 


\section{DEVELOPMENT OF PROGRAM MISSION}

The UMUC Graduate School's mission statement provides a context for the Project Management program's (PMAN) mission. This section describes the process that we used for developing the mission of PMAN.

\section{The UMUC Graduate School's Mission Statement}

UMUC's Graduate School of Management and Technology prepares students for effective leadership and citizenship in a global environment characterized by workforce diversity, increasing competition, and technological innovation. Programs are designed to extend educational access to adult students through multiple formats. The Graduate School strives for excellence in the quality of programs offered and innovative delivery formats. The curriculum provides knowledge of the disciplines with emphasis on leadership, communication, technology, globalization, diversity, systems thinking, critical thinking, information literacy, research competency and ethical practices. The Graduate School challenges students and faculty to continuously demonstrate effective leadership as they apply what they study to their professions and their daily lives. Its goal is to become one of the premiere worldwide graduate institutions of choice among students and faculty.

\section{The Project Management Program's Mission Statement}

The mission of the Project Management specialization of the Graduate School is to deliver a high-quality, graduate-level educational program that prepares project managers and other professionals to manage and lead projects by a set of processes which will contribute quality, efficiency, sound business results and professional integrity to a variety of local and global enterprises. It is also designed for current project managers that want to update their skills. The Program is offered in online, face-to-face and hybrid settings to meet the needs of project management professionals worldwide. Just as project management is present in a variety of settings, students may be admitted to the Program from a variety of educational backgrounds professional experiences, providing the strength of diversity that enhances the educational experience of all students. The Program offers students a foundation to prepare for certification in any of several of PMI's knowledge areas. The quality of the Program will meet or exceed the requirements set forth by the Global Accreditation Center of the PMI®.

\section{Development of Mission Statement}

The Mission Statement for the Program has been formulated by its Program Directors. It has been reviewed by the Chair and Associate Chair of the Information and Technology Systems Department of the Graduate School, where the Program resides. In addition, the Statement has been reviewed by a select group of Program faculty and students. Finally, the Statement has been approved by the Graduate Council which is the academic governing body of the UMUC Graduate School. The composition of the Graduate Council is as follows: Dean, associate and assistant deans, department chairs and administrators.

\section{LEARNING AND PERFORMANCE OBJECTIVES}

The GAC's Handbook of Accreditation defines six domains. The first five of these domains map one-toone to project management process groups, as defined in the $\mathrm{PMBOK} \AA^{3}$. The sixth domain is professional responsibility. The applicant must provide evidence that it sufficiently addresses the following six domains:
- $\quad$ Initiating the Project
- $\quad$ Planning the Project
- $\quad$ Executing the Project
- $\quad$ Controlling the Project
- Closing the Project

\footnotetext{
${ }^{3}$ Project Management Institute. (2004). A guide to the project management body of knowledge ( $3^{\text {rd }}$ ed.), (PMBOK® Guide). Newtown Square, PA: Project Management Institute.
} 
- $\quad$ Professional Responsibility

Each domain itself is divided into a number of sub-domains. A structured process was followed to ensure that domain and sub-domain requirements were addressed by the curriculum. The analysis and evaluation of the candidate program is performed by comparing the program's course syllabi with the Learning and Performance Objectives set forth in the Handbook of Accreditation.

Table 1 shows the scoring criteria used to represent the results of our evaluation:

Table 1: Evaluation Scoring Criteria

\begin{tabular}{|l|l|}
\hline$*$ & The curriculum does not address this topic, but it should be included in the curriculum. \\
\hline$* *$ & $\begin{array}{l}\text { The curriculum addresses this topic. However, the topic is not covered in sufficient detail. In the context of a course, } \\
\text { the course should be revised or the topic should be further addressed in other courses to meet the Performance } \\
\text { Objectives. }\end{array}$ \\
\hline$* * *$ & The curriculum addresses this topic sufficiently to meet the Performance Objectives. \\
\hline$* * * *$ & The curriculum's coverage of this topic is broader than what is prescribed in the Performance Objectives. \\
\hline
\end{tabular}

\section{Sample Domain Coverage}

Each domain is defined, followed by a table showing the scores for that domain. An example is shown below for Domain I - Initiating the Project:

\section{EXAMPLE OF DOMAIN COVERAGE FOR DOMAIN I - INITIATING THE PROJECT}

According to the PMBOK ${ }^{\circledR}$ Guide, the initiating process group "defines and authorizes the project or a project phase." During the initiation phase, the project is aligned with the strategic objectives of the organization or the portfolio which comprises the project. The project may be selected through evaluation of several alternatives to determine which alternative best serves the selection criteria derived from the organizational objectives. Furthermore, project scope, assumptions, and dependencies are specified as part of the initiation phase. See Table 2 regarding Domain I, Initiating the Project.

Table 2: Summary of Coverage of the Sub-domains in Domain I, Initiating the Project

\begin{tabular}{|l|l|l|}
\hline & \multicolumn{1}{|c|}{ Sub-domains } & Score \\
\hline 1.1 & Project Goals & $* * * *$ \\
\hline 1.2 & Deliverables & $* * * *$ \\
\hline 1.3 & Project Management Process & $* * * *$ \\
\hline 1.4 & Project Schedule, Budget, Resource \& Constraints - interaction with stakeholders & $* * * *$ \\
\hline 1.5 & Project Schedule, Budget, Resource \& Constraints - analyzing situations & $* * * *$ \\
\hline 1.6 & Project Strategy & $* * *$ \\
\hline 1.7 & Performance Criteria & $* * * *$ \\
\hline 1.8 & Resource Requirements & $* * * *$ \\
\hline 1.9 & Project Budget \& Schedule - support decision making & $* * *$ \\
\hline 1.10 & Formal Project Charter Document - approval decision & $* * *$ \\
\hline
\end{tabular}

Every project has goals which are set during its initiation phase. The goals are the expected outcomes of the project, and are used later to ensure that the project meets such outcomes.

\section{COVERAGE OF THE REMAINING DOMAINS}

The above process is repeated for all six domains. In the end, the coverage of all domains is summarized, as shown in Table 3: 
Table 3

\begin{tabular}{|c|c|c|c|}
\hline Domain & & Description & Score \\
\hline \multicolumn{4}{|c|}{ Initiating the Project } \\
\hline & 1.1 & Project goals & $* * * *$ \\
\hline & 1.2 & Deliverables & $* * * *$ \\
\hline & 1.3 & Project management process & $* * * *$ \\
\hline & 1.4 & Project schedule, budget, resource \& constraints - interaction w/stakeholders & $* * * *$ \\
\hline & 1.5 & Project schedule, budget, resource \& constraints - analyzing situations & $* * * *$ \\
\hline & 1.6 & Project strategy & $* * *$ \\
\hline & 1.7 & Performance criteria & $* * * *$ \\
\hline & 1.8 & Resource requirements & $* * * *$ \\
\hline & 1.9 & Project budget \& schedule - support decision making & $* * *$ \\
\hline & 1.10 & Formal project charter document - approval decision & $* * *$ \\
\hline \multicolumn{4}{|c|}{ Planning the Project } \\
\hline & 2.1 & Project requirements - interaction w/stakeholders & $* * *$ \\
\hline & 2.2 & Work breakdown structure & $* * *$ \\
\hline & 2.3 & Resource management plan & $* * *$ \\
\hline & 2.4 & Project time \& cost estimates & $* * *$ \\
\hline & 2.5 & Project control & $* * *$ \\
\hline & 2.6 & Project plan & $* * *$ \\
\hline & 2.7 & Project plan approval & $* * *$ \\
\hline \multicolumn{4}{|c|}{ Executing the Project } \\
\hline & 3.1 & Commit project resources - utilizing the work authorization system & $* * *$ \\
\hline & 3.2 & Implement project plan & $* * *$ \\
\hline & 3.3 & Manage project progress - reporting, analysis and measurement techniques & $* * *$ \\
\hline & 3.4 & Communicate project progress & $* * *$ \\
\hline & 3.5 & Implement /carry out quality assurance & $* * * *$ \\
\hline \multicolumn{4}{|c|}{ Controlling the Project } \\
\hline & 4.1 & Measure project performance & $* * *$ \\
\hline & 4.2 & Refine control limits & $* * *$ \\
\hline & 4.3 & Perform timely corrective action & $* * *$ \\
\hline & 4.4 & Evaluate effectiveness of corrective actions & **** \\
\hline & 4.5 & Ensure compliance with change management plan & $* * *$ \\
\hline & 4.6 & Reassess project control plans and practices & $* * *$ \\
\hline & 4.7 & Recognize and respond to risk event triggers & $* * *$ \\
\hline & 4.8 & Monitor project activity & $* * *$ \\
\hline \multicolumn{4}{|c|}{ Closing the Project } \\
\hline & 5.1 & Obtain final acceptance & $* * *$ \\
\hline & 5.2 & Document lessons learned & $* * * *$ \\
\hline & 5.3 & Facilitate administrative and financial closure & $* * *$ \\
\hline & 5.4 & Preserve essential project records and required tools & $* * *$ \\
\hline & 5.5 & Release project resources & $* * *$ \\
\hline \multicolumn{4}{|c|}{ Professional Responsibility } \\
\hline & 6.1 & Ensure individual integrity and professionalism & $* * * *$ \\
\hline & 6.2 & Contribute to the project management knowledge & $* * * *$ \\
\hline & 6.3 & Enhance individual competence & $* * * *$ \\
\hline & 6.4 & Balance stakeholders' interests & $* * * *$ \\
\hline & 6.5 & Interact with team and stakeholders in a professional and cooperative manner & $* * * *$ \\
\hline
\end{tabular}

\section{PROGRAM QUALITY}

This section describes the various measures that we have taken to meet the quality requirements of the mission statement. The quality enhancement program at UMUC is multidimensional and includes faculty selection; faculty training; curriculum and syllabi design and review; a unique computer-based instructional platform; computer labs and library services. 


\section{Quality of the Faculty}

UMUC combines a number of full-time Program Directors, full-time collegiate faculty and adjunct instructors. The Project Management specialization follows the criteria set forth by the Graduate School to hire new faculty who are of high quality and have practical experience, theoretical knowledge and pedagogical insight. Faculty hiring is followed by training and mentoring to develop and retain high quality instructors.

\section{Quality of the Curriculum and Syllabi}

The Program Directors are directed to review and update each course on an annual basis and to make major revisions every three years to the syllabi in order to reflect best practices. Each course in the PMAN curriculum has been reviewed to ensure that the language used is concordant with the language used in PMBOK®. Processes described in PMBOK® are also addressed in one or more of our courses. Each year, instructors review textbooks, case studies and other material to make sure that they represent state of the art and contribute significantly to learning. This review and update process takes into account input from faculty, administrators, and students.

\section{Faculty Support}

The Project Management Program Directors in collaboration with the adjunct faculty establish the curriculum content for courses offered in the program. The Program Directors support the instructors by identifying and incorporating best materials and practices into course design and by establishing a strong working relationship with the faculty. Recent efforts in the PMAN specialization to standardize its curriculum content and Web-ready course materials has provided for uniformity across sections while giving instructors flexibility to customize without sacrificing quality. The Program Directors keep track of all the course revisions, update all course syllabi, and schedule and provide core documents, such as lecture notes, to the faculty for their use. This reduces much of the instructors' up-front work and ensures consistency across sections.

Instructional support specialists are available by phone, e-mail, and face-to-face to answer instructors' technical questions regarding online classroom management, to help improve course materials as requested, and to provide personal training as needed to supplement what is available to all faculty members through the Center for Teaching and Learning (i.e. refresher courses, mentoring, etc.). Future plans to further the support and communitybuilding activities for the benefit of PMAN faculty include conducting synchronous online meetings with instructor groups using multimedia conferencing tools with audio, whiteboard, and recording capabilities.

\section{Students Surveys}

Students are surveyed on a continuing basis to identify needs and potential problems. This survey program is a combination of (1) class student surveys conducted at the end of every class in every semester, (2) a random survey of current students conducted every year at the end of the fall and spring semesters, (3) a survey of alumni conducted every three years by the Office of Institutional Planning, Research and Accountability, and (4) an annual review by a select group of faculty and students (review panel/focus group).

UMUC is committed to excellence in instruction and seeks to assign the most effective faculty to teach its courses. All UMUC faculty members participate in a systematic evaluation process which includes, but is not limited to, student ratings of every course. Evaluations are administered and managed by the Office of Research and Evaluations. Results are reported for the entire class (rather than by individual student), and no results are reported until after the faculty member has turned in his or her final grades. Once the scores have been received and the results tabulated by the Evaluation, Research and Grants office, the results are forwarded to the respective academic office and then the faculty member.

For online classes, beginning three weeks prior to the official last day of class, the online course evaluation form is available in UMUC's online classrooms for a period of seven days. During this period, a pop-up dialog box appears each time the student enters his or her class. The text in the pop-up box invites the student to complete and submit the evaluation form. At the conclusion of the term, academic departments provide feedback to their faculty for individual courses. 
The survey consists of 34 specific questions with sections to identify the strongest features of the course and recommendations to improve the course. Most of the questions are answered by selecting one of the following (strongly agree, disagree, neutral, agree and disagree). These numerical scores are tabulated, summarized and forwarded to the Program Directors for review, including individual score for each question and a summary score for the instructor. The Program Directors then discuss the survey outcome with each faculty with the goal of improving the quality of teaching and learning. Students' comments are also read carefully and are taken into account for course redesign and faculty counseling.

\section{Effective Writing Center}

Effective writing is critical to the intellectual life of university students and graduates. It is the responsibility of the university and its faculty to promote effective writing for the purpose of communicating and as a tool for mastering course content. The Effective Writing Center (EWC) supports this mission at UMUC with a range of services and resources for students and faculty. The EWC features self-study modules such as how to avoid plagiarism. Faculty may direct students with writing problems to the EWC for assistance. UMUC's Online Guide to Writing and Research is located within the EWC's website and is a good basic resource for all students. The EWC also provides online writing tutors who provide detailed feedback on student papers.

\section{UMUC 360 Support}

UMUC 360 Support offers support 24 hours a day, seven days a week for UMUC students, faculty and staff from around the world. This service supports UMUC's proprietary course management system, as well as several support software tools used in UMUC classes. Users can contact 360 by calling a toll-free number or via the Internet.

\section{UMUC Open Computer Labs}

Computer labs are available for faculty and students at several of UMUC's regional sites. The labs offer popular software applications, in addition to specialized software applications for classes.

\section{Faculty Media Lab}

Supported by the Office of Instruction Services and Support, the Faculty Media Lab is a UMUC resource for faculty, course designers and instructional support specialists who are interested in developing multimedia enhancements for online courses. The Faculty Media Lab is dedicated to supporting the development of innovative resources for online teaching in a global academic community. The lab supports those who are interested in creating multimedia enhancements for online courses. Designed to simplify the production of audio, video and graphic resources for the online learning environment, the lab plays a supporting role for post-course development enhancements.

\section{Virtual Academic Integrity Laboratory}

The Virtual Academic Integrity Laboratory (VAIL) is a resource for academic integrity in the classroom. VAIL was designed to help faculty and administrators detect plagiarism, design strategies to reduce opportunities for cheating, promote academic integrity and help students avoid plagiarism.

\section{Library Services}

The Information and Library Services (ILS) provides access to a vast array of library resources and services to UMUC students, faculty and staff worldwide to meet their research needs. Resources and services include books and journal articles, instructional, reference, electronic reserves and document delivery services. ILS relies on technology as its primary mechanism to provide access to resources and services to a dispersed, nontraditional student population. ILS currently provides access to databases and other resources through its web gateway. Users can access the library resources regardless of their location or Internet Service Provider. 
Students, faculty and staff within the state of Maryland may request books to be picked up at the local libraries of the University System of Maryland that is most convenient for them. Those outside of Maryland but within the continental U.S. request books from to be delivered to their homes. ILS also can deliver books to faculty overseas. In addition to its book delivery service, ILS also offers document delivery services to all UMUC students, faculty and staff worldwide for a variety of materials including journal articles and book chapters. Further, at the time of writing of this article, ILS has a collection of 15,451 electronic books (e-books), allowing patrons to retrieve and read entire texts online and download or print selected sections of the text. The real-time availability of e-books has significantly increased ILS's ability to meet the needs of UMUC's global population.

Since 1998, ILS has experienced remarkable growth in its ability to offer online full-text resources to global users. The online resources available to UMUC students have grown to more than 110 databases - many of which provide access to full-text materials that cover a vast array of topic areas. The "FindIt" option allows patrons who have found a citation for an article that is not available in full-text within the database being searched to link to the full-text of the article - if available - in other ILS databases. In addition, "ResearchPort" allows patrons to search multiple databases simultaneously.

\section{INSTRUCTIONAL SERVICES}

Over the past several years, the ILS has made great strides in providing instructional services to students and faculty worldwide. In fall 2005, the ILS introduced UCSP 611, Introduction to Graduate Library Research Skills. This five-week, faculty-mediated, required course provides an in-depth introduction to the library research process and the tools necessary to be effective in the Graduate School. Students learn to efficiently and effectively use a variety of electronic retrieval systems including the online catalog of the University System of Maryland and Affiliated Institutions, UMUC's subscription databases, and the web.

The ILS staff members provide online instruction sessions, supplement instruction with web-based tutorials and subject guides, and also serve as visiting online faculty in various classes. In addition, UMUC's librarians provide a number of face-to-face library instruction sessions for UMUC's students. UMUC faculty at any of our satellite locations can request library instruction at any time. The ILS provides UMUC faculty with a librarian assigned to serve as a liaison between ILS and specific UMUC departments in order to communicate information about ILS resources and services, upon request, to assist in designing assignments, to provide library instruction to students and/or workshops for faculty, and to provide research assistance upon request.

\section{REFERENCE SERVICES}

The ILS uses a variety of methods to provide reference services to students worldwide, including e-mail, web-based forms, online chats, telephone and instant messaging. Between 2004 and 2008 there has been a 10\% increase in the number of reference requests. Asynchronous chat service began in April 2001 and is extremely popular with users. According to an exit survey, $96 \%$ of users in 2008 found the service to be an excellent or good experience, and $95 \%$ would recommend the service to a friend. ILS chat service allows librarians and students to work together, pursuing a search strategy through multiple databases or web pages. In addition to improving convenience for users, this approach allows superior point-of-need instruction to students. Instant messaging (IM) reference services began in March 2006. The use of IM has increased 55\% between 2007 and 2008.

\section{DOCUMENT DELIVERY SERVICES}

In 1998, the ILS initiated an electronic reserves program to make required readings available within online classrooms, after copyright clearance has been obtained by ILS staff. Growth has averaged $16 \%$ per year between 2004 and 2008 with 14,664 readings requested in 2008. E-reserves are currently used in 1,884 online classes, and feedback on the quality of the e-reserves service from both students and faculty has been very positive. Interlibrary loan and document delivery services continue to grow steadily. The volume of electronic document delivery requests submitted increased an average of 10\% per year between 2004 and 2008. Patrons can conveniently request an article not available in full-text within the library's databases by clicking on the "FindIt" button and selecting the DocumentDelivery option. Journal articles and book chapters are delivered electronically to patrons via the web in 
PDF format. Using "DocumentExpress," a state-of-the-art document management platform introduced in 2005, ILS staff processed, retrieved and delivered more than 15,000 requests in 2008.

\section{STRATEGIC PLANNING}

This section describes the process that we used for developing the strategic plan for PMAN, which is designed to be consistent with the UMUC strategic plan. The PMAN plan has been reviewed by the Graduate School Council which consists of the dean of the Graduate School, associate deans, staff and department chairs. Finally, the strategic plan has been reviewed by a PMAN panel of select instructors and students.

\section{Business and Learning Models}

The business model favored by UMUC and the PMAN specialization is to offer the same fixed curriculum (no electives) of classes in each of the three Master of Science Programs, presented for accreditation: Master of Science in Information Technology (ITEC), Master of Science in Technology Management (TMAN) and Master of Science in Management (MSMN). The basic business concept is to maintain the same curriculum for project management, independent of the degree program in which it is offered, supporting as many sections as needed to meet the growth in enrollment. The PMAN specialization is offered face-to-face and online three times a year (summer, spring and fall). This model optimizes growth at minimal cost and with minimal disruption.

The learning model is focused on a student-centric approach to learning in a network-centric environment. A student-centric approach means that students proceed through the curriculum at their own pace and are responsible for the quality of their learning. A network centric approach entails that both students and faculty are engaged through participation and feedback. Students are given many opportunities to communicate with peers, participate in team projects and access the instructor. The Internet-based tools at their disposal include a chat room, e-mail, posting, discussion and work groups and collaborative writing tools. All of these tools are supported by the course management platform. A phone bridge also is available in support of real-time audio communication.

\section{Strategic Directions}

The following key strategies support the Program's goal of providing a "high quality program that meets the needs of working professionals, residing in the State of Maryland, the U.S., and global locations" Our strategic focus is on quality in all of its dimensions, but we cannot ignore other critical strategic aspects including growth and technology.

\section{GROWTH}

In these times of economic stress, it is difficult to predict enrollment growth. Since its inception as a specialization, PMAN enrollment has grown at an average annual rate of $18 \%$ over the last five years. UMUC's goal is to achieve an annual growth rate in enrollment of $7 \%$ to support its operations. We believe that our growth rate will meet the University's growth rate goal over the next five years and might even exceed it. The growth in UMUC enrollment is stimulated by the dissemination of information, in the form of marketing, public relations, advertisements and word of mouth from current to prospective students.

UMUC's current status as a global Registered Education Provider (REP) contributes to this growth. Accreditation by PMI/GAC in the year 2009 provides a competitive advantage and supports continued substantive growth in student enrollment.

Project management knowledge, processes, skills, methods and techniques can be applied to a wide variety of domains from information technology to construction, health care administration, and defense. This realization opens new vistas for the application of project management principles to these specialties on a local and global basis. 


\section{QUALITY}

The focus of our strategic plan is quality. This includes quality of the teaching staff, the program curricula and syllabi which are consistently monitored while utilizing student feedback. Systematic surveys ensure that quality of the program and quality of its support services are above our goals. The plan is to continue expanding all the aspects of our quality program.

\section{TECHNOLOGY}

The UMUC program is strongly dependent on technology to give students ready access, speed of communication and response, as well as the availability and use of state of the arts tools and techniques that facilitate learning.

Most UMUC students (about 95\%) prefer to take classes online. Nevertheless, a small part of the students' population prefers face-to-face classes. UMUC will continue to offer its classes face-to-face at its three local (in Maryland) campuses: College Park, Dorsey Station and Shady Grove to meet the needs of all its students. UMUC is constantly on the lookout for alternative methods of course delivery. One possibility under investigation is the use of hybrid (partially both face-to-face and online) courses.

UMUC unveiled the new generation our proprietary course management platform in spring 2009. This new Internet-based platform written in Java is more robust, offers enhancements, accommodates a larger number of students, and offers a variety of new tools and techniques in support of both teaching and learning. Some of our courses use software packages (e.g., Microsoft Project, Crystal Ball), learning objects, recent articles, cases and guest speakers. UMUC plans to continue expanding the set of tools, techniques, methods and solutions to support both teaching and learning

\section{LESSONS LEARNED}

UMUC has been offering a Project management specialization for five years. We currently have approximately 3,000 master's level students enrolled in the specialization. For the last four years we have been a Registered Education provider (REP) under Project Management Institute (PMI) and we have been accredited by the Global Accreditation Center of PMI since November 2009. In the process of securing and maintaining accreditation we have learned a few important lessons that might be valuable for other institutions of higher learning interested in following the same path.

One of the most valuable lessons is that if you focus on quality all other goals will follow. This means the quality of the faculty (selection, training, promotion and support); the quality of the curriculum and syllabi; the quality of the instruction; and the quality of support services such as student enrollment, student guidance, writing support, computer labs, and computer support. Of all those aspects, the continuing attention to the quality of each course is fundamental. The Graduate School policies require that all courses be reviewed annually and that at least a third of all courses be revised. Besides looking at textbooks, case studies, etc., an important focus is on learning aids for students, including learning objects, guest speakers, and the use of multimedia.

UMUC also surveys students annually for satisfaction and support services to evaluate course and faculty performance. This survey is conducted annually for current students and every three years for the Program alumni. The surveys provide valuable input for faculty retention, student retention, student services, and course design.

Preparation of the self study, review meetings with the onsite visiting team, and annual reports to PMI provide an organization like UMUC with additional discipline and guidance to achieve its mission and goals. 